\title{
KEEPING TRACK OF SCIENTIFIC DIVES IN COUNTRIES WITH INCIPIENT DIVING PROGRAMMES: THE SCIDIVE RECORD FORMS
}

\author{
Bernabé Moreno \\ Carrera de Biología Marina, Universidad Científica del Sur, Lima, Peru
}

\begin{abstract}
Pre-dive checks and dive logs are fundamental documentation for any diving operation and must be incorporated as mandatory 'good operating practices' in scientific diving (SD) projects. Data included in dive logs may vary in detail, however, there is basic information to provide based on global standards. Differently to several developed countries in Europe, North America and Australasia, there are countries with incipient, sometimes non-regulated, SD programmes. In this article the importance of documentation in SD is highlighted and record forms are provided as templates, including versions both in English and Spanish. The Diving Supervisor (DS) is the designated person to fill the 'Daily SciDive Log' and 'SCUBA \& surface-supplied LogSheet' (Table 1,2 and 3, respectively), whilst every diver is responsible for filing their own 'SciDiver's Digital LogBook' (Table 4). General and specific considerations for all tables are described throughout the text. This effort was done to facilitate systematic data management and start developing the bases towards solid national/regional standards on scientific diving operations, particularly for those countries with incipient (scientific) diving programmes. Keywords: scientific diving, dive logs, hyperbaric conditions, risk assessment, good operating practices.
\end{abstract}

\section{ARTICLE INFO}

PolHypRes 2020 Vol. 72 Issue 3 pp. $29-38$

ISSN: 1734-7009 elSSN: 2084-0535

DOI: $10.2478 /$ phr-2020-0015

Pages: 10, figures: 1 , tables: 4

page www of the periodical: www.phr.net.pl

Publisher

Polish Hyperbaric Medicine and Technology Society

\section{Original article}

Submission date: $15.02 .2020 \mathrm{r}$.

Acceptance for print: 27.03.2020 r. 


\section{INTRODUCTION}

Scientific diving (SD) is one of the most insightful and cost-effective research tools used by researchers from a bewildering array of disciplines including benthic ecology, marine geology, maritime archaeology, and hyperbaric medicine [1,2,3,4]. Considered within the spectrum of occupational diving [5], SD falls into different regulations depending on the continent, region, or country of operation, for example: the 'Approved Code of Practice (ACOP) for Scientific and Archaeological Diving Projects' of the Health \& Safety Executive, UK [6]; the 'Operation of Scientific Divers' of the German Commission for Scientific Diving [7]; the 'Polish Occupational Health and Safety Regulations for Underwater Works' [8,9]; the 'Occupational Diving Operations-Standard Operational Practice' [10]; and the 'Standards for Scientific Diving Manual' of the American Academy of Underwater Sciences, USA [11]. These regulations and standards separate consolidated SD programmes from those that are only just emerging.

Dive logging is a 'good operating practice' taught by diving agencies and organisations worldwide including the recreational, technical, commercial, and military domains (or 'sectors' sensu Wienke and O'Leary [12]). Each one of these demands different levels of logging; however, the general aim is quite similar; to keep a systematic record of the immersions conducted by each diver during diving operations. Additionally, the dive log is a necessary evidence for compliance of the requirements (prerequisites) for more advanced courses or specialties, independent of the diving domain $[13,14]$. Both pre-dive checklists and briefings cover a parallel function; however, these are designed as part of risk management endeavours to prevent incidents and accidents at work [15]. For SD operations, the design and implementation of the abovementioned should be of common practice in research conducted under hyperbaric conditions. Logged dives and related metadata are useful to detect trends and make quantitative analysis of historical data [16]; assess the risks associated to diving operations [17]; use them as evidence in diving incidents/accidents investigations [18]; find information and visual resources effortlessly (personal observation); and contribute to the transparency and open data availability in scientific research [4].

Within the South American region, Peru is a clear example of a country with an incipient diving programme [19]. In countries where the overall occupational background of divers is underdeveloped and proper regulations are non-existent, only a minimum of control can be exerted from individual research units. A recent outlook of the operations executed by divers from the 'Universidad Científica del Sur' (CIENTIFICA Divers) emphasised the need of systematic data management for its inherent capability of keeping track of diving operations [19]. I hereby provide three different forms to be used in research operations relying on SD. Since the most common diving modes used for benthic studies differ in some attributes (Fig.1 (a) SCUBA [SelfContained Underwater Breathing Apparatus], and (b) surface-supplied diving), each one requires a different log form. Forms are presented from general to specific. The first one, Daily SciDive log (Table 1), includes general information about the diving operation and it should be completed by the Diving Supervisor (DS) in charge during each day of fieldwork. A pre-dive briefing is here demanded. The second ones are both SCUBA \& Surfacesupplied Logsheets (Table 2 and 3, respectively) for cumulative dives undertaken during a single diving project. Effort is made to record times in order to integrate, synchronise or concatenate with other electronic devices such as cameras, data loggers and diving computers. Finally, I provide the SciDiver's digital logbook (Table 4), a very detailed form which should be completed by each scientific diver after every day of operation and shared with the DS for compilation. All forms and additional metadata are recommended to be kept in internal repositories or made freely available in online project repositories (e.g., GitHub, https://github.com/).

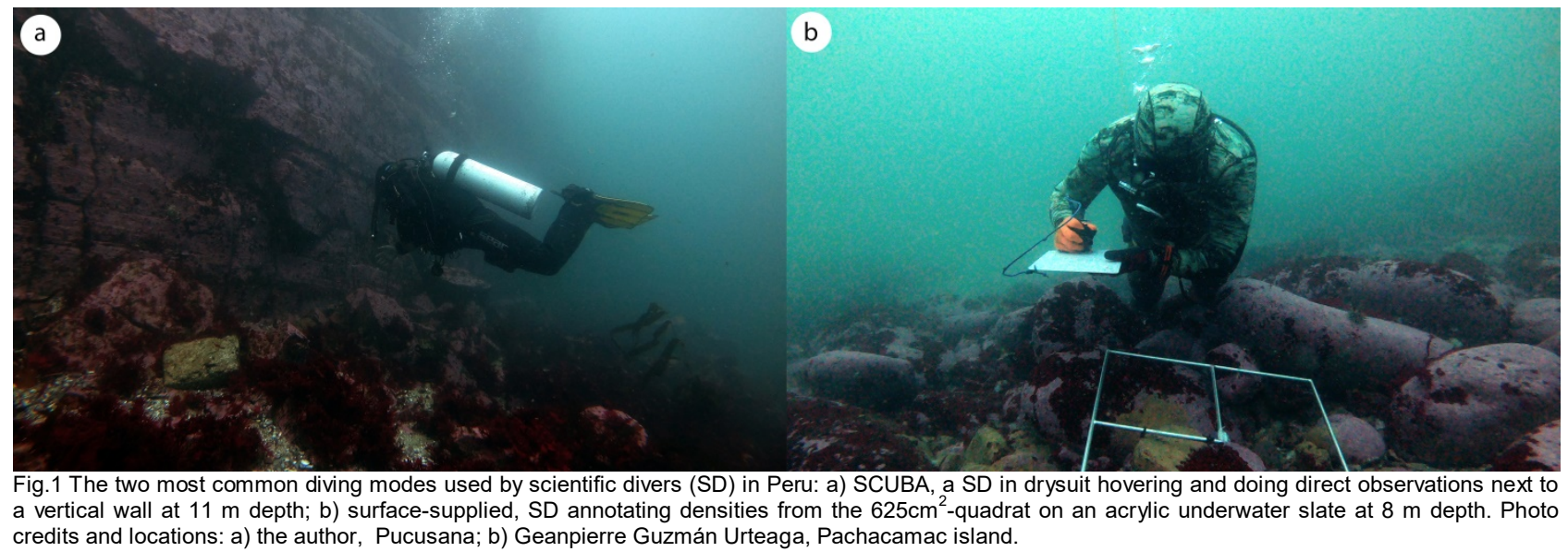




\section{GENERAL CONSIDERATIONS FOR SCIDIVE RECORD FORMS}

There are some common considerations to bear in mind during form filling. Time: Date to be provided in YYYY/MM/DD format since this enables sorting in date order (oldest-to-newest logs, or vice versa). This is particularly functional for digital files and it is compatible with ex situ codifications of material such as photo/videoquadrats [20]. 'Left-surface' and 'emergence' times (to obtain 'total decompression time' sensu [21]), surface interval (SI) between dives should be annotated since this is one of the most important consideration for decompression planning (in the case of multi-level and multiple dives per day). It is highly recommended to set and synchronise all electronic equipment and logs to the GMT+00:00 time zone, by doing so, you can have an unequivocal and less erratic base-standard in case the SD team operates at different longitudes (hence, different time zones). Space: Location will be provided with common names of the site, sampling-station codes (in case of monitoring surveys or revisits), but most importantly, it should be georeferenced (geographic coordinates, indicating the 'zone and hemisphere' if the UTM system is used). Since SciDive forms are not limited to hyperbaric conditions at sea, fundamental information such as altitude (meters above sea level, m.a.s.l.) and surface barometric pressure (atm/bar) need to be registered since it is a mandatory input for obtaining the theoretical depth as part of the decompression planning for altitude diving (i.e., >300 masl) $[3,22]$.

\section{DAILY SCIDIVE LOG}

Safety first. Emergency numbers (e.g., coastguards, hyperbaric centres, ambulances, firefighters) should be indicated and on hand to aid timely responses if any diving-related accident occurs. Daily SciDive log numbers (No.) should have unique values that are not repeated in the files of the SD unit. The responsible organisation and project name (including acronym) should be stated at the beginning since this will be part of further codification in the following tables (forms). Distinction should be made between the project leader (or principal investigator, PI) and the diving supervisor (DS). The DS is responsible for conducting risks assessments, ensuring that scientific divers are fit to dive (i.e. have an approved medical examination); and are capable of conducting the planned underwater tasks (complying with the certifications and capacitation requirements); management, execution and supervision of diving operations and emergency procedures (if needed); registration, collection, and digitalisation of the forms. She/he can be assisted by a secondary DS. Both supervisors can also act as divers, however, the responsibilities should be re-arranged so that each participant only plays the role they are supposed to. All divers involved must sign, adding their maximum certification, agency code and provide valid insurance (e.g., Divers Alert Network, DAN). Diving modes (SCUBA surface-supplied, or CCR [Closed Circuit Rebreather]) and configuration (back-mount/sidemount and bailout; single cylinder or twinset) should be indicated.

It is recommended to briefly describe conditions at surface by annotating average ambient temperature, wind direction and speed (knots, kn), visibility, cloud formation, and other valuable environmental information. A daily pre-diving briefing should be undertaken ideally before embarking so all SD team members, assisting staff and crew are aware of the activities to be conducted. The decompression procedure should be indicated to know which one has been used to plan the dives. Since dive computers are the primary method for decompression planning in recreational and scientific diving $[17,23]$, the brand, model, and the algorithm (e.g., RGBM, VPM) should be noted. Incidents and accidents must also be reported in this form. These include (but are not restricted to) the report of equipment failure (once identified, failing gear should be tagged correspondingly and not used until maintenance), report of decompression sickness (DCS; indicate the diver, circumstances, times and actions taken), report of other medical issues, report of other incidents (e.g., reasons for aborting a dive), and other emergencies. 
Daily SciDive Log

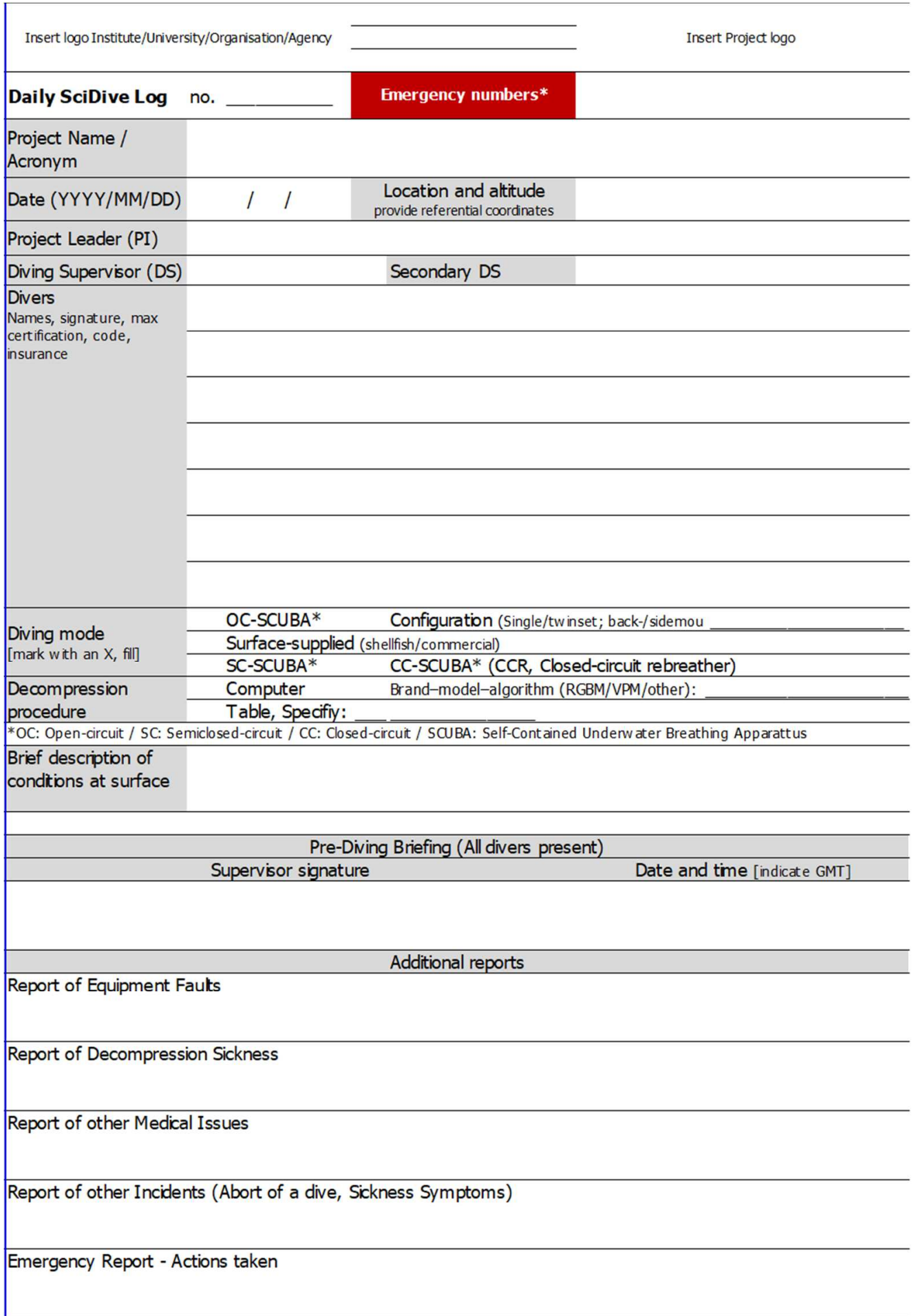

`Emergency numbers in Peru, dial: 106 for 'SAMU (Sistema de Atención Médica Móvil de Urgencia)', (01) 4535746 for Coastguards in Callao, Lima, (01) 4335049 for the 'Centro de Medicina Hiperbárica' (Hyperbaric Medicine Centre), 116 for firefighters. For coastguards across Peruvian departments: https://www.dicapi.mil.pe/directorio?field grupo telf tid=154\&title=. Other emergency numbers can be found in https://www.gob.pe/547-telefonos-deemergencia. 
SCUBA SciDive Log Sheet.

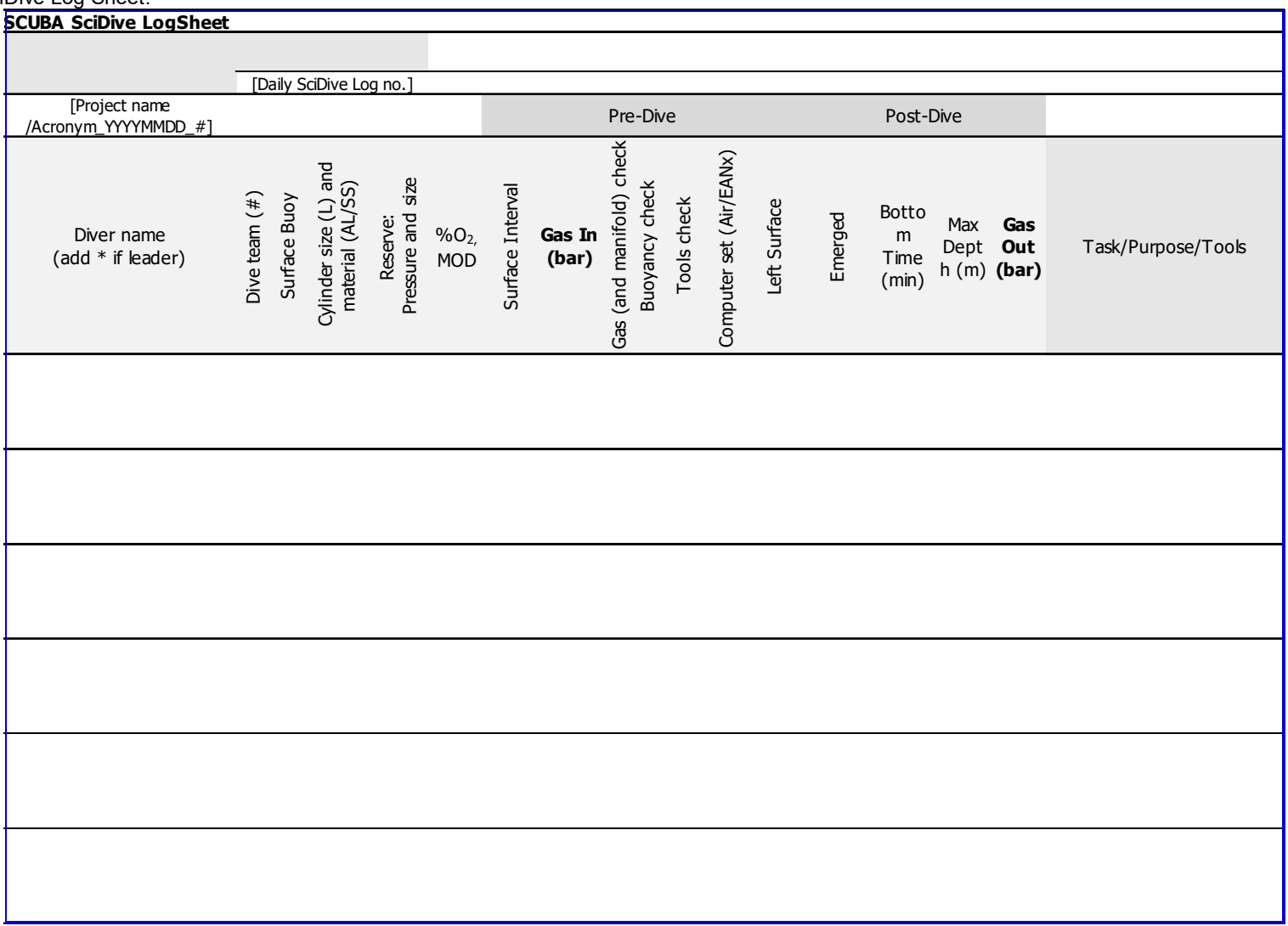

Surface-supplied SciDive LogSheet.

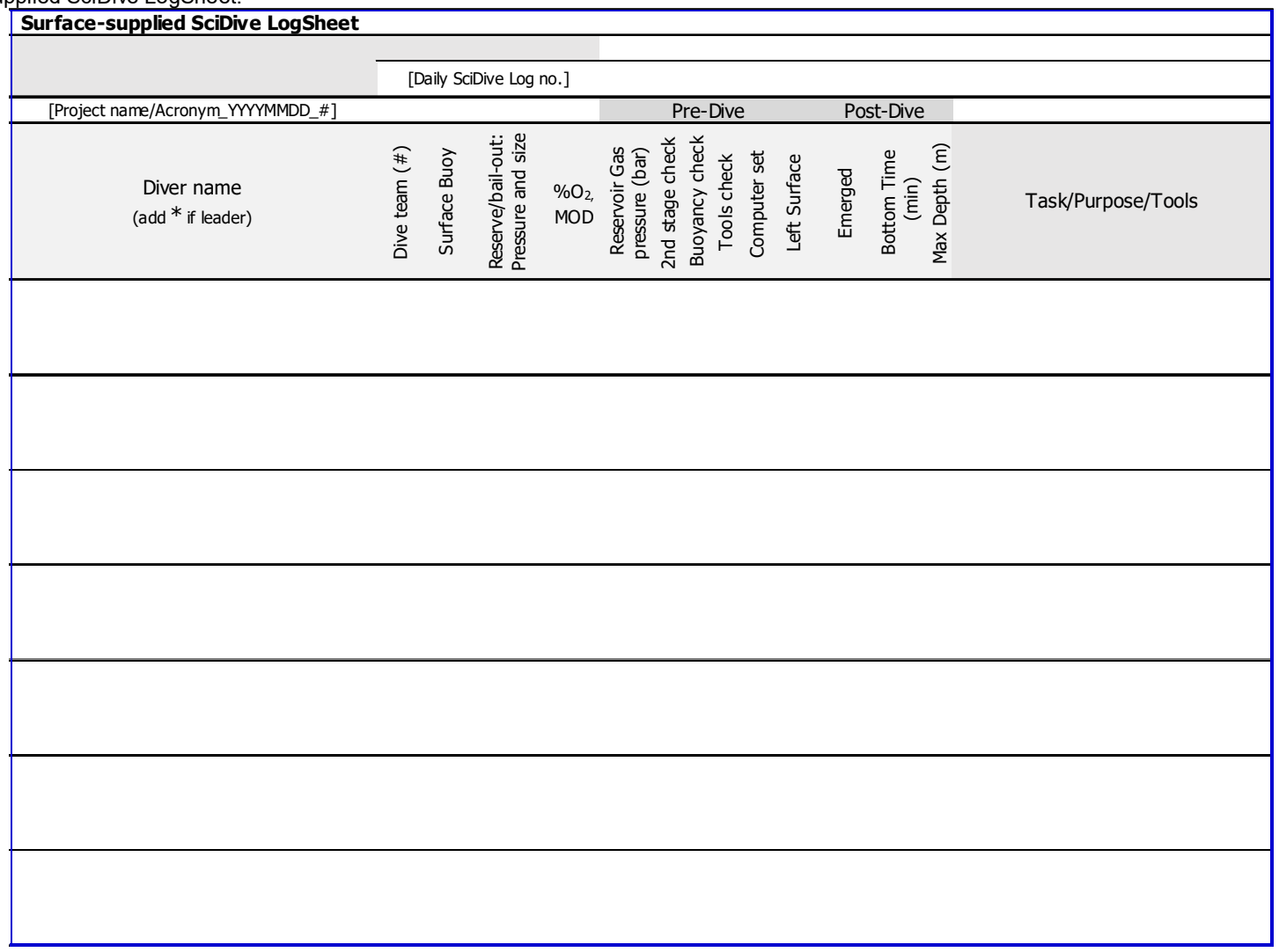




$$
\|
$$




\section{SCUBA \& SURFACE-SUPPLIED SCIDIVE} LOGSHEET

On the one hand, logsheets of both diving modes bear some resemblances between each other, including information on the breathing gas mixture, which is typically air $\left(\mathrm{O}_{2} 21 \%\right)$ but can also be Enriched Air Nitrox (e.g., EANx32, EANx36) where the Maximum Operating Depth (MOD) must be stated. Pre-dive checks include verifying gas (valves, second stages, hoses and pressure); buoyancy check (weight belt, buoyancy compensation device [BCD]); verifying all tools required for underwater work are being carried (e.g., underwater camera rig, quadrats, sampling bags, acrylic slates, transect tape, lift buoys); and that the diving computer is set up to the gas mixture accordingly. Once the diver is back on the surface, times are annotated (bottom, and total decompression times) and completed tasks are recorded including any other observation or event. On the other hand, some relevant differences exist between these two diving modes (Fig.1). According to [6] the minimum dive team for benign conditions using SCUBA is three: the supervisor (DS), diver and buddy; while it is four when using Surface-supplied: DS, tender, diver and stand-by diver [6]. SD is built under a team-based approach, therefore leadership (identified with an * in the tables), chain of command, and tasks should be fixed prior to any dive and repeated during the pre-dive briefing.

The task of carrying the surface buoy should be assigned to one of the divers (buddy) and marked accordingly in the logsheet. This is mandatory for SCUBA because harsh seas, or surface reflections, may interfere with the surface team's ability to identify the divers' location by observing their bubbles as they break surface. Regarding gas containers, SCUBA depends on the use of cylinders as the source of gas mixture. These can be of aluminium (AL) or steel (S), and their volumes (l) can vary (e.g., $7,12,15$ or 18), as well as the number of cylinders (singles, independent doubles or twinset) and their configuration (back-/side-mounted); while surfacesupplied depends on an air compressor at the surface and the hoses acting as an umbilical connecting the components. To determine the consumption of breathing gas mixtures, 'Gas In' and 'Gas Out' (in bar or PSI) are key variables to record for better management and further planning. However, this is less accurate for surfacesupplied diving. The person tending the equipment from the surface must make sure that the compressor pressure gauge reads between 8-16 bar (115-225 PSI) [24] and if any problem emerges tether signals should be used to communicate surface-to-diver and vice versa (e.g., [25]).

\section{SCIDIVER'S DIGITAL LOGBOOK}

Once underwater, a proper logbook starts to be built when annotations and general in situ observations are recorded to either underwater slates (Fig.1b) or multimedia (ideally chronologically synchronised) ('Hyperlink to multimedia' in Table 4). The nature of the content of this logbook will much depend on the scientific discipline and objects of study, however, from an ecological point of view important and common annotations may include (i) biotope/habitat type (e.g., kelp forest/bed, barren ground, rocky/coral/artificial reef, seagrass meadows); (ii) substrate type (landslide rocks, boulders, cobbles, sands, muds), (iii) slope (vertical wall, plateau, overhang), (iv) rugosity [26]; (v) biocenosis attributes (densities, behaviours, interactions, rare sightings) and (vi) horizontal visibility. The SciDiver's digital logbook builds from the data recorded in the previous forms, but there are some fields that require revisiting the dive computer; these include max depth, average temperature, and temperature at max depth. Modern dive computers have either a data cable, an interface, or can wirelessly download data to a portable computer. These specs are very useful since the whole diving profile is kept there and it may offer key insights into diving incidents resulting in accidents or fatalities [18].

Research units conducting SD operations should take advantage of the automatic logging of electronic devices to systematically manage data collected during diving operations. The SciDive record forms represent an effort to do so using a bottom-up approach, building from a research unit operating in a country with an incipient (scientific) diving programme towards a more regulated occupational background.

\section{ACKNOWLEDGMENTS}

This work was conceived during the execution of projects funded by the Universidad Científica del Sur. Thanks are due to the Heriot-Watt Scientific Diving Team for providing practical skills during fieldwork in Orkney, Scotland. Thanks to Geanpierre Guzmán for the images portraying the author while doing underwater annotations in Fig.1b.

\section{DisCLOSURE STATEMENT}

The author declares no conflict of interest.

\section{REFERENCES}

1. Balazy P., Kuklinski P., Włodarska-Kowalczuk M. Scientific diving in polar regions - the example of ecological studies at the Institute of Oceanology, Polish Academy of Sciences. Polish Hyperbaric Research. 2014; 46(1):65-75. DOI 10.13006/PHR.46.4

2. Kur J., Mioduchowska M. Scientific diving in natural sciences. Polish Hyperbaric Research. 2018; 4(65): 55-62. DOI 10.2478/phr-2018-0024

3. Pardo A. A scuba diving direct sediment sampling methodology on benthic transects in glacial lakes: procedures description, safety measure and test results. Environmental Science and Pollution Research. $2014 ; 21: 12457-12471$. DOI 10.1007/s11356-014-3011-8

4. Tourtas A., Papadimitriou K., Karadimou E. Schill R.O. Diving as a Scientist: Training, Recognition, Occupation - The "Science Diver" Project. Underwater Work, Sérgio António Neves Lousada, IntechOpen. 2020; DOI: 10.5772/intechopen.94601

5. Doolette D.J., Mitchell S.J. Hyperbaric Conditions. Comprehensive Physiology. 2011; 1:163-201. DOI 10.1002/cphy.c091004

6. Health \& Safety Executive HSE. (2014) Scientific and archaeological diving projects. Approved Code of Practice and Guidance. Available from: https://www.hse.gov.uk/pubns/books/l107.htm [Accessed October 2019]

7. Kommission Forschungstauchen Deutschland, KFT. GUV-Rule. Operation of Scientific Divers. 2006. Available from: https://publikationen.dguv.de/Regelwerk/DGUV-Regeln/1018/Einsatz-von-Forschungstauchern. [Accessed June 2019] 
8. Act on the Underwater Work "Ustawaz dnia 17 pazdziernika 2003 roku o wykonywaniu prac podwodnych (Dz. U. $2003 \mathrm{nr} 199$ poz. 1936 )". Journal of Laws No 199/2003 item 1936. 2003

9. Kot J., Sićko Z. New Polish Occupational Health and Safety Regulations for Underwater Works. International Maritime Health. 2007; 58: 1-4.

10. Australian/New Zealand Standards. Occupational Diving Operations - Part 1: Standard operational practice, AS/NZS 2299.1:2007. 2015

11. American Academy of Underwater Sciences, AAUS. Standards for Scientific Diving Manual; Alabama, 77pp. 2019. Available from: https://www.aaus.org/AAUS/About/Diving_Standards/AAUS/Diving_Standards.aspx [Accessed February 2021]

12. Wienke B.R., O'Leary, T.R. Diving and Dive Computer History. In: Understanding Modern Dive Computers and Operation. 2018; SpringerBriefs in Computer Science. Springer, Cham. DOI 10.1007/978-3-319-94054-0_1

13. Jablonsky J. (2001) Getting Clear on the Basics: The Fundamentals of Technical Diving. Global Underwater Explorers (GUE), 142pp.

14. Professional Association of Diving Instructors, PADI. Instructor Manual. California, USA. 200pp. 2020. Available from: https://prosblog.padi.com/tag/instructor-manual/ [Accessed June 2020]

15. Catchpole K., Russ S. The problem with checklists. BMJ Quality \& Safety. 2015; 24:545-549. DOI 10.1136/bmjqs-2015-004431

16. Sayer M.D., Barrington J. Trends in scientific diving: an analysis of scientific diving operation records, 1970-2004. International Journal of the Society for Underwater Technology. 2005; 26(2), 51-55. DOI 10.3723/175605405783101458

17. Jóźwiak D., Siermontowski P., Dąbrowieckil Z., Olszański R. Analysis of the risk of diving accidents in military and recreational diving. Polish Hyperbaric Research. 2015; 4(53), 41-54. DOI 10.1515/phr-2015-0022

18. Sayer M.D., Azzopardi E. The silent witness: using dive computer records in diving fatality investigations. Diving and Hyperbaric Medicine 2014; 44(3):167-9. PMID: 25311326

19. Moreno B., Indacochea A., Cóndor-Luján B., Pacherres C.O. Environments, tools and trends of benthic surveys by Peruvian scientific divers: an outlook of the operations executed by 'Universidad Científica del Sur'. Manuscript in preparation (a).

20. Moreno B. A simple in situ labelling approach and adequate tools for photo and video quadrats used in underwater ecological studies. Underwater Technology. 2020; 37(1), 29-33. DOI 10.3723/ut.37.029

21. Direction of Commander, Naval Sea Systems Command. U.S. Navy Diving Manual. Revision 7. 2016.

22. Moreno B., Ramirez D.W., Rodriguez L., Aliaga-Barrena D. Diversity of autotrophs collected by divers at a high-altitude Andean lake. Manuscript in preparation (b).

23. Wright S., Hull T., Sivyer D.B., Pearce D., Pinnegar J.K., Sayer M.D.J, Mogg A.O.M., Azzopardi E., Gontarek S., Hyder K. SCUBA divers as oceanographic samplers: The potential of dive computers to augment aquatic temperature monitoring. Scientific Reports. 2016; 6: 30164. DO 10.1038/srep30164

24. Humphrey A., Grossman S., McBurney J., Sheldrake S. Use of Surface-Supplied Gas for Scientific Diving. In: Pollock NW, ed. Diving for Science. Proceedings of the American Academy of Underwater Sciences 30th Symposium. Dauphin Island, AL: AAUS; 2011.

25. Pasotti F., Guillaume C., Saucéde T., Danis B. Diving Activity Report - Scientific diving mission along the Gerlache Strait (West Antarctic Peninsula) 27th February - 20th March 2019. Belgica 121. $2019 . \quad$ Available from: https://www.researchgate.net/publication/333079404_Diving_Activity_Report_Scientific_Expedition_Belgica_121_Feb-_Mar_2019 [Accessed January 2021]

26. Friedman A., Pizarro O., Williams S.B., Johnson-Roberson M. Multi-Scale Measures of Rugosity, Slope and Aspect from Benthic Stereo Image Reconstructions. PLoS ONE. 2012; 7(12): e50440. DOI 10.1371/journal.pone.0050440

\section{Bernabé Moreno}

Carrera de Biología Marina

Universidad Científica del Sur, Lima, Peru

e-mail: bmorenole@cientifica.edu.pe

ORCID identifier No: 0000-0002-9751-6307 